\title{
RELATIONSHIP BETWEEN MORPHOLOGICAL PARAMETERS AND THROWING VELOCITY, MAXIMAL FORCE AND SWIMMING SPEED IN ELITE MALE WATER POLO PLAYERS
}

\author{
Kemal Idrizović ${ }^{1,2}$, Julio Calleja-Gonzáles ${ }^{2,3}$, and Dean Kontić ${ }^{4,5}$ \\ ${ }^{1}$ Faculty for Sport and Physical Education, University of Montenegro, \\ Podgorica, Montenegro \\ ${ }^{2}$ Center for Health, Exercise and Sport Sciences, Belgrade, Serbia \\ ${ }^{3}$ Faculty of Sport Sciences, University of the Basque Country, Vitorija-Gasteiz, Španija \\ ${ }^{4}$ University of Dubrovnik, Dubrovnik, Croatia \\ ${ }^{5}$ Australian National Water Polo Team
}

\section{SUMMARY}

Technical, tactical and physiological demands of water polo players that once were standard are no longer current. The advancement in the total approach to this discipline, from players', coaches' and also from the scientific standpoint, have led to the establishing of new physiological principles that are now actual in this team sport. The relationship of morphological characteristics and specific motor abilities represents one of the important traits of a player profile in elite water polo. The main aim of this study was to examine and define the relationships among the anthropometrical characteristics (body height, arm span, leg length, body mass and BMI) and three sport-specific fitness tests, 20-meters-sprint-swimming, maximal dynamometric force in eggbeater kick and throwing velocity. The sample of participants embraced $22(23.04 \pm 2.72$ years) top-quality water polo players, members of the national team and one water polo club, who participated in the Adriatic League competition. Throwing velocity shows a significative correlation only with maximal dynamometric force in eggbeater kick $(r=.455, p=.033)$. Maximal dynamometric force in eggbeater kick, except with throwing velocity shows significative correlation with body mass $(r=.745, p=.000)$, body height $(r=.568, p=.006)$, BMI $(r=.521, p=.013)$ and with arm span $(r=.488, p=.021)$. Regarding to swimming speed, significant correlations were not found. One of the major finding of the present research was that swimming speed has no statistically significant linear correlation with any of applied morphological and specific motor parameters. A second major result was that throwing velocities significantly correlate only with maximal dynamometric force in eggbeater kick. On the other side, no statistically significant correlation has been found between a throwing velocity and the applied anthropometric parameters that almost completely determined a result in the test for the estimation of a maximal dynamometric force in eggbeater kick.

Key Words: anthropometry, correlation, specific fitness.

\section{INTRODUCTION}

Water polo is practised as a sport activity, namely as a sport game for more than a one and a half century. During that time the rules and a way of playing were changed many times. Technical, tactical and physiological demands that once were a standard, are no longer current. The advancement in the total approach to water polo, both from players' and coaches' and a scientific standpoint has led to the new physiological principles that are current in this sport discipline. Current rules and principles also are not 
given for all times, because the development of water polo enfolds and a continual scientific treatment is necessary in order to obtain the current knowledge. The actual and relevant scientific findings should be, first of all, helpful to water polo players, their coaches and also for the scientists whose topic of research is water polo game.

In this moment water polo is a team sport characterized by a high-intensity, intermittent activity pattern. Players have been reported to perform around 100 high-intensity and sprint activities during waterpolo match play (Smith, 1998). The same author argues that water polo is very intermittent, with intense bursts of activity occurring and activity varying according to the players' positions in the pool. Thence, for example, Melchiorri, Castagna, Sorge, and Bonifazi (2010) analyzed blood lactate among elite male water polo players and found $7.7 \pm 1.0 \mathrm{mmol} / 1$ of blood lactate concentration, but with enormous differences among playing positions. The mean match bloodlactate concentrations for Center Forwards (Centers), Center Defenders (Points), and Field Players (Drivers and Wings) were (in mmol/l) $11.2 \pm 1.0,6.7 \pm 0.9$, and $5.3 \pm 0.9$, respectively, indicating the different physiological backgrounds of the water polo game for each playing position.

Smith (1998) has observed that elite male water polo players have approximately $6-20 \%$ greater oxygen consumption than competitive swimmersand also mentions that $\mathrm{VO}_{2}$ max values are moderately high $(58-61 \mathrm{ml} / \mathrm{kg} / \mathrm{min}$ ) in national-level water polo players, that is also lower than those reported for trained swimmers (63-69 $\mathrm{ml} / \mathrm{kg}^{-1} / \mathrm{min}^{-1}$ ) (Fernandez \& VilasBoas, 2012). Also, a number of studies have shown that $\mathrm{VO}_{2}$ max is higher for international level swimmers than water polo players (Cazorla \& Montpetit, 1988). In his recent study Meckel et al. (2013) highlights thatelite water polo players demonstrated lower repeated sprint ability (RSA), aerobic and anaerobic capabilities compared to elite swimmers.

Therefore, water polo is a game which from players demands a considerable strength to hit, block, and push other players during game play (Van der Wende, 2005). These are also basic influencing that, the basic characteristics of the elite water polo playerincludes high levels of strength, swimming speed and leanbody mass, and specific technical and tactical capabilities (Lozovina \& Pavčić, 2005). Beside this, throwing velocity is considered to be one of the most important aspects of performance of water polo players (Van der Wende, 2005).

As it can be seen, contemporary water polo is characterised by fast and attractive match play, and often mutual contact of players, demanding the spe- cific morphological traits from the players (Lupo, Tessitore, Minganti, \& Capranica, 2010).

The morphology of an athlete, namely his anthropometric characteristics represent an exceptionally important factor in every sports discipline, thence the same is true for water polo. Because of this, the top players are selected and shaped, for generations, on the basis of actual demands of water polo game and individual characteristics of eachplayer's profile.

Among other things, these are some of the major factors that have led to the following conclusions that anthropometric characteristics of elite water polo players have changed over the last (analyzed) 28 years. Body shape changed in terms of greater height and more elongated limbs, with thinner waist and broader shoulders. Body mass increased. Muscle-to-fat mass ratio increased. These observed changes are consequence of population secular trend and sport morphological adaptation (optimization) (Lozovina, Lozovina, \& Pavičić, 2012).

Beside mentioned reasons, very important reasons for explaning the existing anthropometric differences between water polo players from certain countries are also differents in water polo schools, which much depend on morphologic properties of these environments. So, for example the obvious differences among Greek (Tsekouras et al., 2005) Croatian (Lozovina, Durovic, \& Katic, 2009), Spanish (Ferragut et al., 2011a) and Montenegrin (Idrizović, Uljević, Ban, Spasić, \& Rausavljević, 2013) elite water polo players.

Taking into account both morphologic and motor potentials of top-quality water polo players (Ibid) highlight the differences existing also on that level. The authors come to the fact that top elite water polo players are of the same anthropometric characteristics as the elite, and that they accomplish the same maximal swimming velocity, however they have the statistically significant higher level of throwing velocity and the manifestation of a maximal force.

Therefore, all previously mentioned characteristics of water polo game and its changes during the time, lead to the need for the permanent check of correlations inside and between the morphologic and motor profile of a contemporary top water polo player. Such researches have led to the information that can indicate the changes in the specificity of mutual correlation of anthropometric indicators and physical performances of elite water polo players, and for author's knowledge there is no scientific evidence about same studies.

Therefore, the aims of the present study were to determine relationship between specific fitness po- 
tential throwing velocity, swimming speed and maximal dinamometric force in eggbeater kick and fundamental morphological parameters (body height, arm span, body mass and BMI) in elite male water polo players.

\section{METHODS}

\section{Sample of participants}

The sample of participants embraced twenty-two (23.04 \pm 2.72 years) elite water polo players, members of the national team and one water polo club, who participated in the Adriatic League competition. All participants must be active members of the national team and water polo club team during current season.

The players participated voluntarily and gave their written consent. The study was designed in compliance with the recommendations for clinical research of the World Medical Association Declaration of Helsinki (2013) and reviewed and approved by the local ethics committee.

The study was performed in two phases during two last weeks of March of 2013. The first phase was performed during last two matches of Montenegrin national water polo team in the framework of qualifications for World league in water polo 2013, and which also was a part of preparation for 15th FINA World Championship in Barcelona. During two days, firstly anthropometric, on the second day, functional motoric testing were carried out. The second part of testing, which was carried out in an identical way as the previous, was related to the testing of players of water polo club, and it was carried out in approximately the same time interval, as the previous measurement, and during which the players would be in a standard competition training program in the framework of Adriatic Water Polo League matches.

\section{Sample of variables}

Anthropometric measurements were taken following the International Society for the Advancement of Kinanthropometry (ISAK) protocol (Marfell-Jones, Olds, Stew, \& Carter, 2006). Leg length (LL) was measured for all the participants according to (Barry \& Maria, 2010). The anthropometric measurements were taken in the morning by two certified technicians (Level II ISAK anthropometrist). Body height in $\mathrm{cm}$ $(\mathrm{BH})$ was measured using a SECA-222 telescopic measuring rod, with a precision of $1 \mathrm{~mm}$ and a range $(60-230 \mathrm{~cm})$, while body mass in $\mathrm{kg}(\mathrm{BM})$ was assessed by a SECA-875 flat scale, with a precision of $0.1 \mathrm{~kg}$ and a range ( $0.0 \mathrm{~kg}$. a $130 \mathrm{~kg}$ ) (Seca Instruments Ltd., Hamburg, Germany). Leg lenght was measured with
Siber \& Hegner GPM anthropometer of the Martin type and arm span (AS) with Lufkin W606PM anthropometric tape.

In addition, body mass index was determined. Body mass index (BMI) or Quetelet index was calculated from body height and body mass values using following formula:

$$
B M I=\text { weight }(\mathrm{kg}) / \text { height }\left(\mathrm{m}^{2}\right)
$$

The water-polo-specific fitness was evaluated by: swimming sprint over a 20 metre distance, a water polo drive shoot test and dynamometric semi-tethered force test.

The swimming sprint test over a 20 metre distance (20M) was commenced upon a sound signal, similar to sprinting for ball possession at the start of a game. The head was kept out of the water during the test (water polo front-crawl). The subjects started in the water from either a front-on or side-on position. Their head remained behind the laser beam which marked the 0 -metre starting point. When signalled, the subjects swam as fast as possible for 20 metres. A Longines swimming timing apparatus was used.

Throwing velocity was measured by a drive-shoot test (SHOOT). Each subject was instructed to lift the ball from the water surface and throw it into a goal net as fast as possible. The examiner was positioned with a velocity-detecting radar (Speedster Radar Gun Bushnell, Overland Park, Kansas, USA) behind the net.

The semi-tethered dynamometric test (DYN) consisted of maximum intensity upright swimming using an eggbeater kick with a fast elastic line fixed to a special belt. An 'eggbeater kick' is a hands-free form of treading water that allows a swimmer to remain vertical and/or move in a vertical position. An athlete's legs mainly alternate between one-legged breaststroke kicks. This form provides continuous support because there are no breaks in the kick. The swimming force was recorded with the use of a tensiometric dynamometer coupled to a MAX-5 device (JBA Staniak, Poland) via a WTP 003 amplifier and Max 5.1 computer software. The subjects were instructed to perform the eggbeater kick as hard as possible and to achieve the maximal possible drag force. The maximal force achieved was recorded by the examinees and included in the data analysis.

\section{RESULTS}

Table 1 shows the basic statistical parameters of anthropometric indicators of elite water polo players, and their results about specific motor tests. The val- 


\section{TABLE 1}

Basic statistical parameters of anthropometric indicators of

elite water polo players, and their results about specific motor tests.

\begin{tabular}{lrrrrrr}
\hline & $M$ & \multicolumn{1}{c}{ Min } & Max & \multicolumn{1}{c}{ SD } & \multicolumn{1}{c}{ Skew. } & \multicolumn{1}{c}{ Kurt. } \\
\hline BH & 187.79 & 180.00 & 199.00 & 4.90 & .35 & -.21 \\
\hline AS & 193.66 & 183.40 & 203.00 & 5.45 & .03 & -.72 \\
\hline LL & 101.75 & 94.00 & 110.70 & 4.32 & .05 & -.11 \\
\hline BM & 93.04 & 79.20 & 120.00 & 9.77 & 1.16 & 1.65 \\
\hline BMI & 26.36 & 22.80 & 33.20 & 2.37 & 1.30 & 2.36 \\
\hline 20M & 11.04 & 10.40 & 12.05 & .44 & .94 & .35 \\
\hline SHOOT & 75.04 & 65.00 & 82.00 & 5.57 & -.24 & -1.12 \\
\hline DYN & 43.55 & 36.00 & 58.00 & 5.94 & 1.07 & .36 \\
\hline
\end{tabular}

Legend: M - Sample mean; Min - Minimum; Max - Maximum; SD - Standard deviation;

Skew. - Skewnis; Kurt. - Kurtosis; BH - Body height; AS - Arm span; LL - Leg

length; BM - Body mass; BMI - Body mass index; 20M - Swimming sprint test over a

20 metre distance; SHOOT - Throwing velocity was measured by a drive-shoot test;

DYN - Semi-tethered dynamometric test.

\section{FIGURE 1 and 2}

The scatter plots and line of best fit for the relationship between the body height and arm span ( $p=.000)$ and body height and leg length $(p=.000)$.

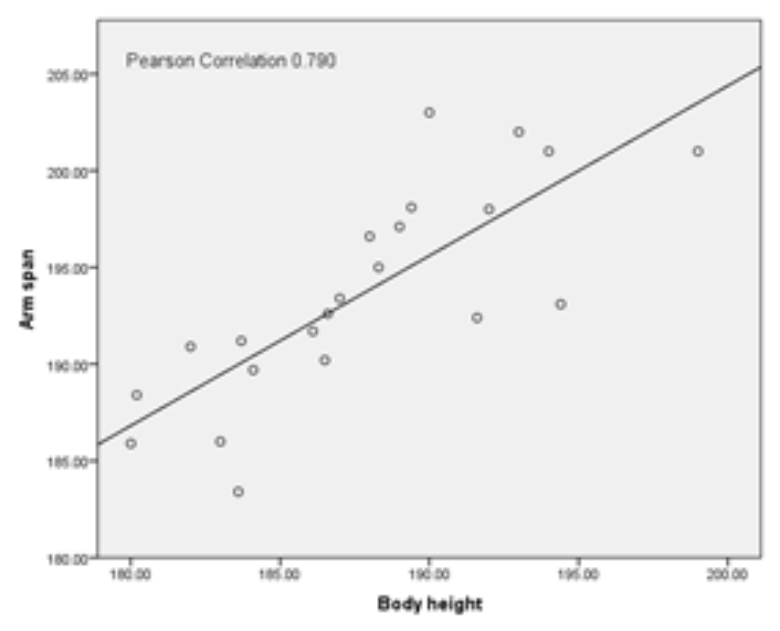

ues of coefficients of asymmetryand peakedness for body mass and BMI (Skew. $=1.302$; Kurt. $=2.366$ ), as for the specific motor tests SHOOT (Kurt.=-1.125) i DYN (Skew. $=1.072$ ) indicate to the important characteristic of distribution of results of these tests.

Relationships between specific physical fitness and morphological parameters were also analyzed, and different significant correlations were found. Of 28 calculated correlation coefficients 11pairs had the statistically significant relation (Figure 1 to Figure 11). With regard to body height, significant correlations were found with arm span $(r=.790 ; p=.000)$, leg length $(r=.714 ; p=.000)$, body mass $(r=.509 ; p=.016)$ and DYN ( $r=.568 ; p=.006)$. Regarding to arm span, except with a leg length, significant correlations were found between this parameter and leg length $(r=.611 ; p=.002)$,

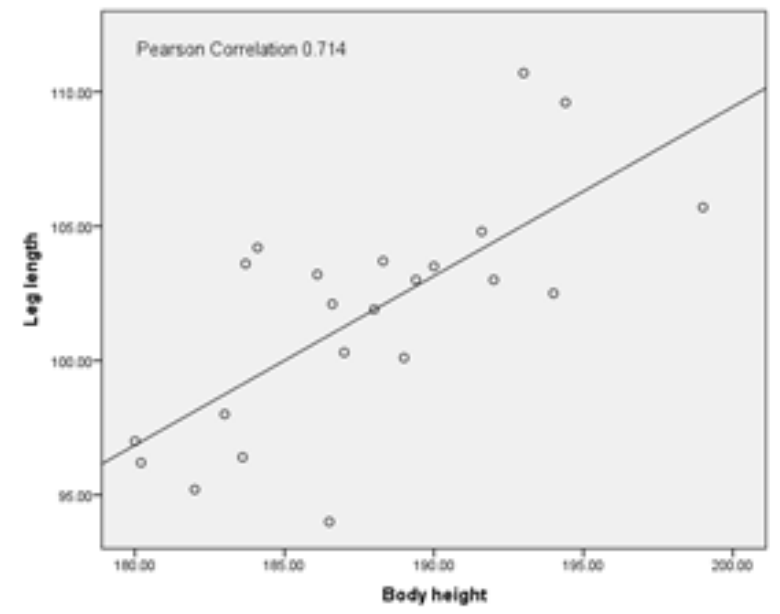

body mass ( $r=.512 ; p=.015)$, and DYN ( $r=.488 ; p=.021)$. Regarding the leg length, except with body height and arm span, significant correlations were not found. To the body mass, except witha body height and arm span, significant correlations were found with BMI $(r=.860 ; p=.000)$ and DYN $(r=.745 ; p=.000)$. To the BMI, except with a body mass, significant correlation were found with DYN ( $r=.521 ; p=.013)$. Regarding 20M specific motoric test, significant correlations were not found. Regarding specific motor test SHOOT, only one statistical relation was found and it was with a specific motor test DYN $(r=.455 ; p=.033)$. On the other side, on the basis of previously said it can be seen that a motor test DYN achieved a statistically significant correlation with body height, arm span, body mass, BMI and SHOOT. 


\section{FIGURE 3 and 4}

The scatter plots and line of best fit for the relationship between the body height and body mass $(p=.016)$ and body height and dynamometric force $(p=.006)$.
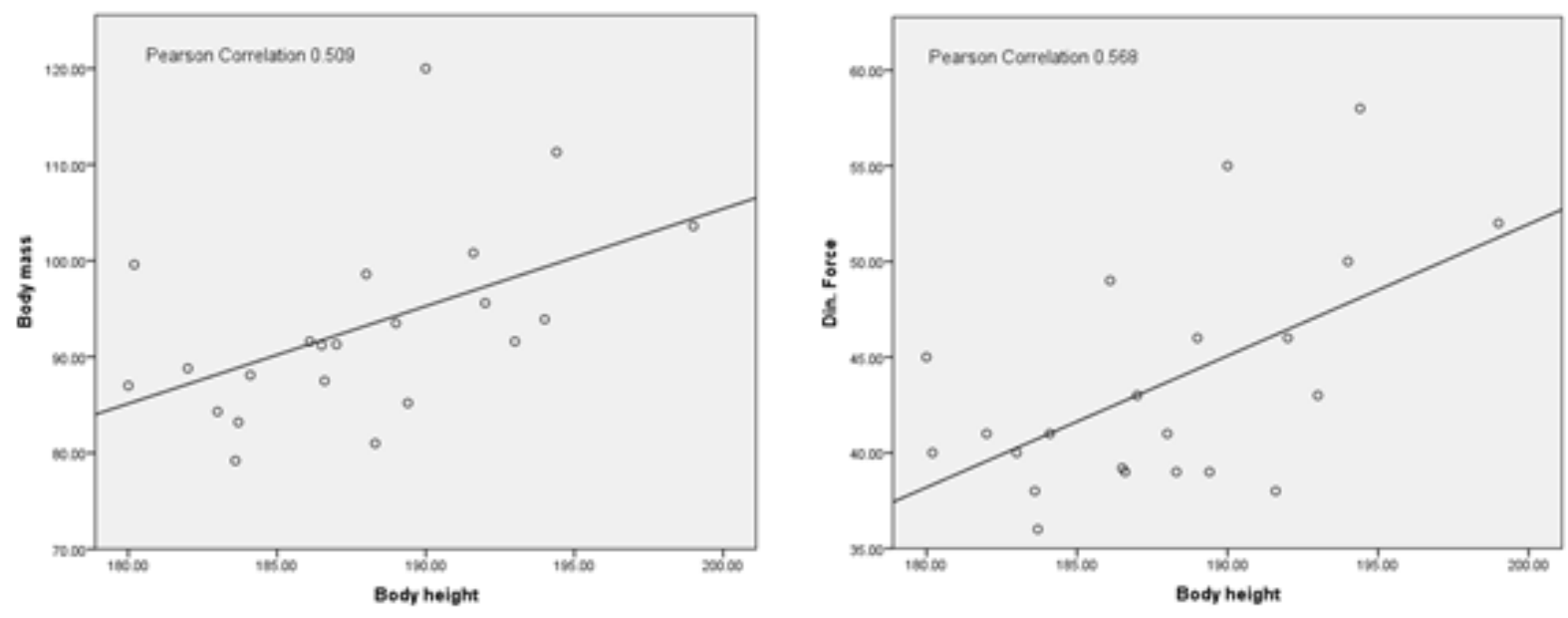

\section{FIGURE 5 and 6}

The scatter plots and line of best fit for the relationship between the arm span and leg length ( $p=.002)$ and arm span and body mass ( $p=.015)$.
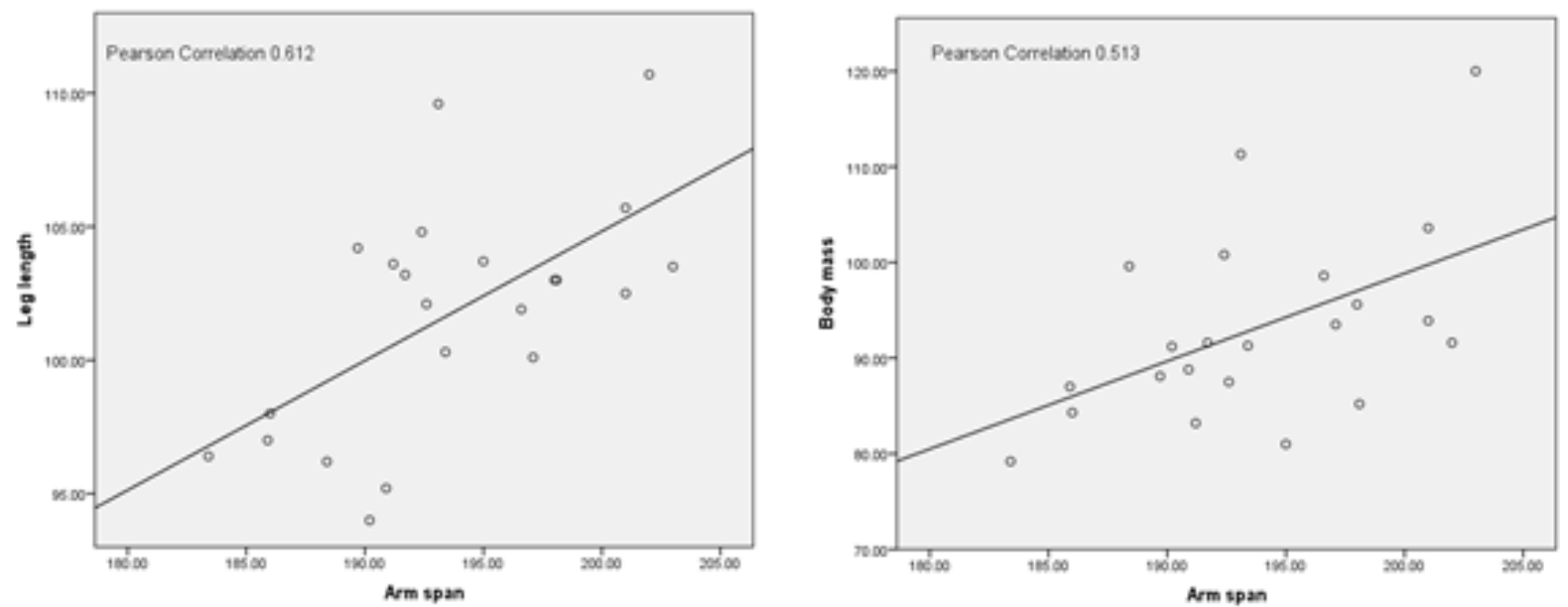

\section{FIGURE 7 and 8}

The scatter plots and line of best fit for the relationship between the body mass and BMI ( $p=.000)$ and arm span and dynamometric force $(p=.021)$.
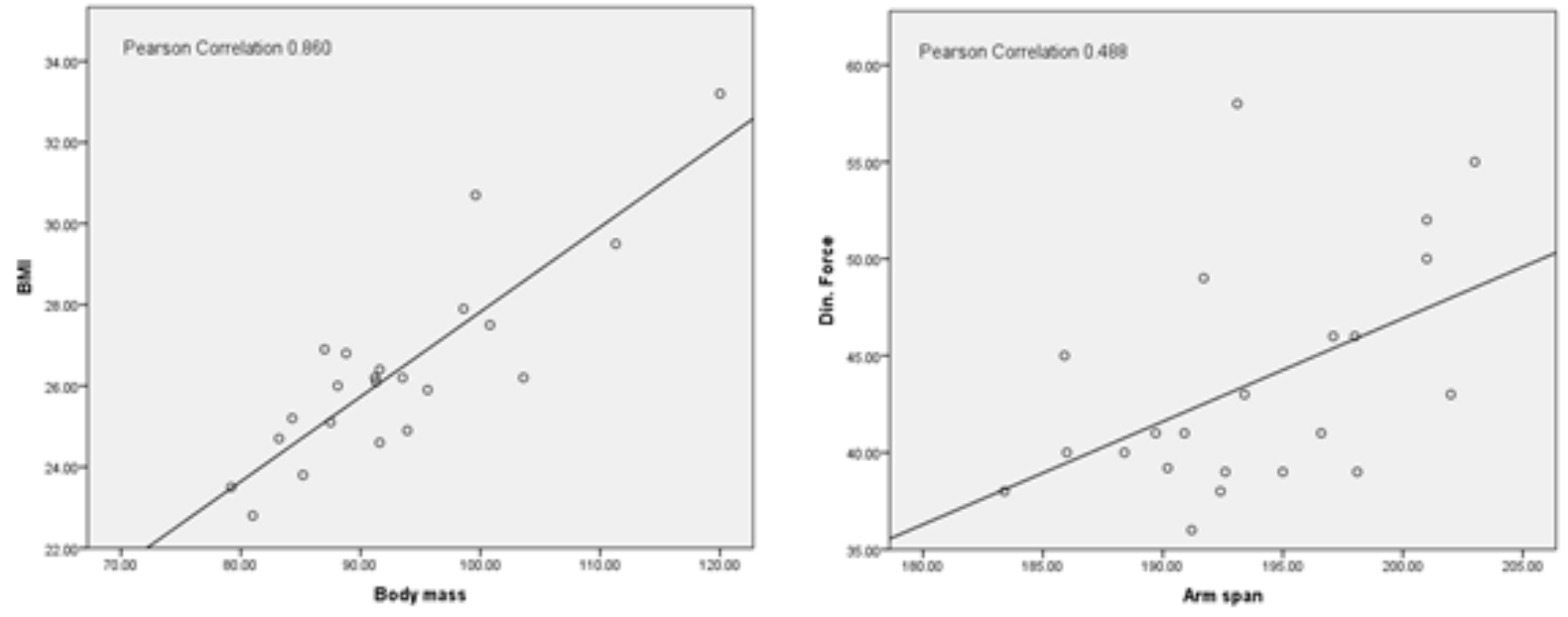


\section{FIGURE 9 and 10}

The scatter plots and line of best fit for the relationship between the body mass and dynamometric force $(p=.000)$ and BMI and dynamometric force $(p=.013)$.
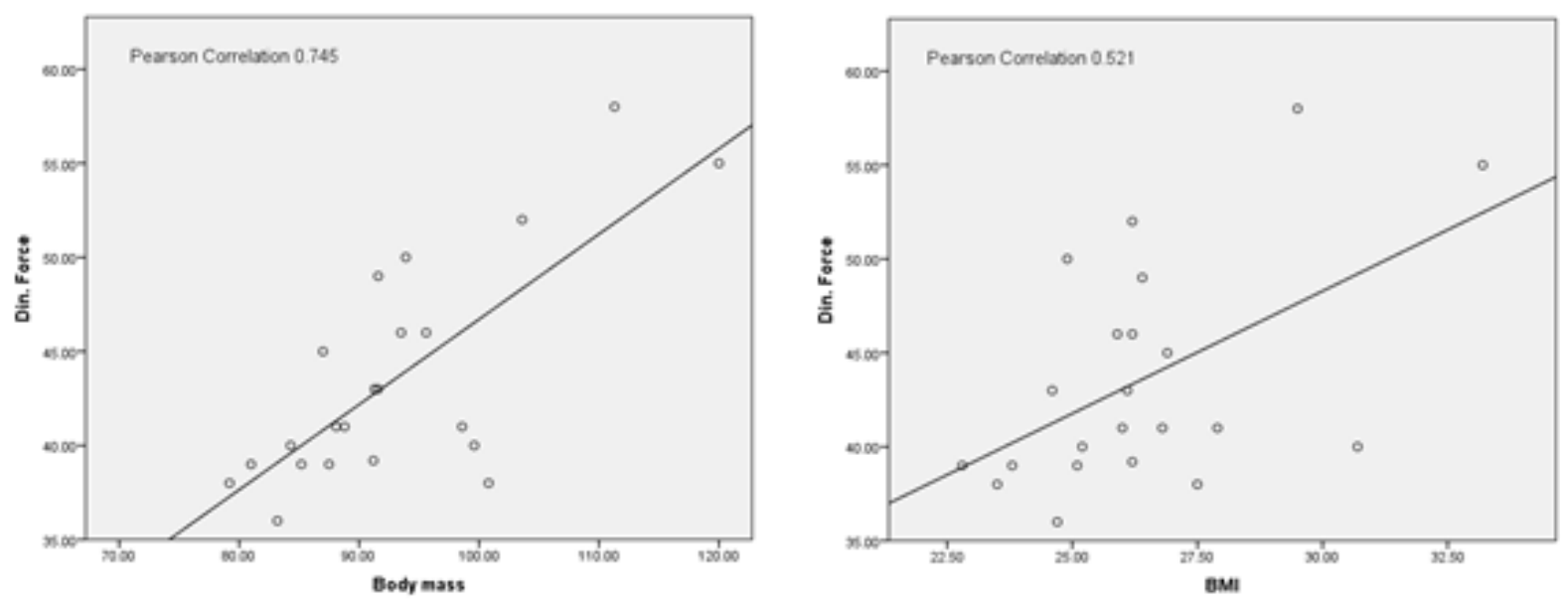

FIGURE 11

The scatter plot and line of best fit for the relationship between the SHOOT and dynamometric force $(p=.033)$.

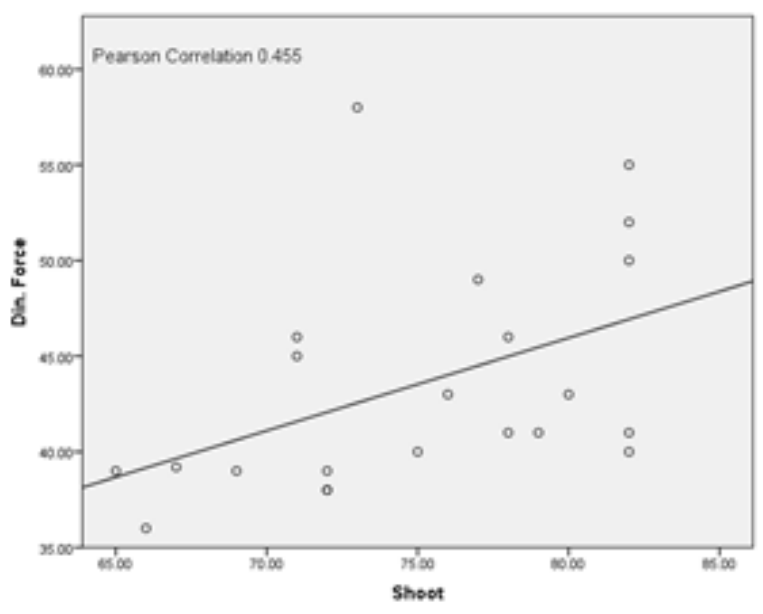

\section{DISCUSSION}

This study was conducted to determine relationship between specific fitness potential throwing velocity, swimming speed and maximal dinamometric force in eggbeater kick and fundamental morphological parameters (body height, arm span, body mass and $\mathrm{BMI}$ ) in elite male water polo players.

The last evidence certified that physiologically and psychologically, water polo is a very demanding and mentally challenging sport (Snyder, 2008).

First of all, water polo represents a physically very demanding sport discipline. As such, it demands a very quality level of physical conditioning from the athletes practising this sport activity. This, first of all, means a very developed strength, specific endurance, speed and coordination. Actually, the quality of a physical conditioning in a contemporary top water polo often brings an advantage to one of teams andit wins a match game because of this advantage. At the top level of water polo competitions, tacticallytechnical skills are very equalised, thence the small differences in a physical potential of water polo players of both sides can be decisive for the results of a match. The performing of mental tasks set by the game, significantly depends on a current physical status, thence the physical potential of an athlete, on this area of demands of water polo game, has also a very important and often a decisive impact.

As in all sports, strength training is of great value in enhancing successful water polo performance. There are several muscle groups utilized in the basic actions of throwing a ball as well as in swimming head up and eggbeatering (Ibid). Just these water polo potentials, as the basic physical quality of a top water polo player, were the topic of this research.

To our knowledge, this is the first study that to concurrently define and investigate the relationships 
among basic morphological parameters and throwing velocities, swimming speed and maximal forceof elite male water polo players. One of the major finding of the present research was that swimming speedhas not a statistically significant correlation with any of applied morphologic and specific motor parameters. A second conclusion was that throwing velocities significantly correlate only with DYN, while not any statistically significant correlation with the indicators of longitudinal dimensionality was found. Despite this, in the athletic throwing disciplines, a longitudinal dimensionality represents one of the main factors of results, because the stable support for a thrower is constantly present. In water polo, the stability of lower body that is constantly variable, and it can be realized with a quality egbbeater kick, is very important for the quality of throwing, while the attributes of a longitudinal dimensionality generally do not emerge as an important predictor of a throwing velocity.

The values of standardised coefficients of skewness and kurtosis indicate the fact that the values of morphological indicators for a body mass and BMI, what is shown by high positive values of these statistic parameters, distributed in the field of lower values and that the finite high values of these parameters make exceptions, meaning that the elite water polo players in this study, for these two parameters are grouped around the value of an arithmetic mean and that a small number of exceptions is located in high positive values. The proof of such a statement is also a relation of the arithmetic mean with a maximal and a minimal result.

The water polo players from this research showed mean values of height of $187.79 \mathrm{~cm}$. These values are in consonance with previous data reported by Lozovina and Pavičić (2005), Smith (1998), and Villa et al. (2009). Although a body height of water polo players in all these researches is almost identical, Montenegrin water polo players with an average body mass of $93.04 \mathrm{~kg}$ were heavier for several kilograms than their colleagues from Spain, Croatia and Greece.

Statistically significant relations that were found in this research among the morphologic indicators of longitudinal dimensionality: body height, arm span and leg length are the relation to parameters of the same measurement topic and, as such, these are in accordance with all previous works, both on athletes and general population, what is the result of the standard proportions of human body parts.

The results of this study showed that the mean arm span measure exceeded stature measure in elite water polo players, consistent with other studies, which treated a general population (Goon, Toriola, Musa,
\& Akusu, 2011; Reeves, Varakamin, \& Henry, 1996; Steele \& Chenier, 1990), and the studies that tested elite water polo players (Ferragut et al., 2011b; Idrizović, Milošević, \& Pavlović, 2013; Kondrič, Uljević, Gabrilo, Kontić, \& Sekulić, 2012).

Highly statistically significant correlation between arm span and stature $(r=.790)$ observed in our sample is consistent with a big number of other studies which found strong associations between arm span and stature. For example, Reeves, et al. (1996) reported a correlation coefficients $(r=.73-.89)$ indicated a clear association between arm-span measurements and height in all groups of that research.

An exceptionally important result obtained in this study is related to a swimming speed of elite water polo players. Of all applied morphological and specific motor indicators neither of them had shown a significant correlation with a result in the test 20M. On the basis of such results, it can be concluded that a swimming velocity of elite water polo players is not defined by any of the following parameters: body height, arm span, leg length, body mass, body mass index, maximal dynamometric force in eggbeater kick and throwing velocity. Such a result can suggest to the statement that a swimming speed of water polo players is most probably determined by the quality of their swimming technique and maybe some other fitness characteristics, what was not a topic of this research. Such conclusion is in accordance with previous research Dopsaj, Matković, and Zdravković (2000) who are saying that a maximal swimming speed, especially at sprint distances, depends on pulling force characteristics besides technical and energetic abilities of swimmers. Also, according to Siders, Lukaski, and Bolonchuk (1993), the anthropometric variables: body height, body mass, percent body fat and fat-free mass have an effect on swimming performance in female swimmers, but not in males. Anderson, Hopkins, Roberts, and Pyne (2008) also argue that the combination of fitness and technique factors were important for competitive performance. However, Zampagni et al. (2008) highlights that a body height is one of the best predictors in short, middle and long-distance events, but not for male ultra-endurance swimmers an open-water ultra-swimming contest, as stated by (Knechtle, Baumann, Knechtle, \& Rosemann, 2011). On the basis of all previously said it can be stated that the morphological parameters are more important determinants in a competition swimming, while for the swimming speed in elite water polo, it is most probably the swimming technique.

Unlike the previous researches where a throwing velocity had a statistically significant correlation with 
the anthropometric indicators (Bloomfield, Blanksby, Ackland, \& Allison, 1990), such a statement is not proven in this study, what, on the other side, entirely correspond to the findings by Ferragut et al. (2011b) and Alcaraz et al. (2012), who also shown that the anthropometric indicators used in these studies did not accomplish a statistically significant correlation with a throwing velocity. A very interesting data is one offered by Milanović and Vuleta (2013) presenting that a body height, body mass and arm span have no correlations with player's performances in offensive and defensive activities. Just because of all mentioned and regardless of all changes in water polo game in last thirty years, a statement by Joris, Muijen Van, Ingen Schernau Van, and Kemper., (1985) saying that a speed of the ball toward the goal post is an essential characteristic in this sport and depends on the muscular force, technique, and suitable synchronization of different corporal segments even today can be considered as fully acceptable. Beside this, the data given by Ferragut et al. (2011a) saying that this specific physically-technical quality at all playing positions behaves entirely differently according to the anthropometric indicators depending if a goalkeeper is at the goal, not at the goal or player is moving before the shoot, telling about the complexness of a shoot velocity dependence of various abilities and characteristics of a water polo player.

The only statistically significant correlation in this research is the correlation accomplished by a throwing velocity with a specific motor test DYN that consisted of maximum intensity upright swimming using an eggbeater kick with a fast elastic line fixed to a special belt.

The eggbeater kick is a rotational movement of the lower legs in which a swimmer opens the legs sideways with the hip joint flexed and bends the knees while swivelling both feet in opposing circles (Homma, 2000). Sanders (1999) highlights that the eggbeater kick is a cyclic movement structure of the lower limbs with the activity of the right and left sides being similar but opposite in phase, meant to sustain the body in the elevated position or to push the opponent's body strongly. Also, Sanders (1998) argues that two skills are used to raise the upper body for the purpose of shooting for goal. One of them is a „boost" in which the upper body is driven upward explosively to achieve maximum height. The second is a "hold" in which the body is maintained in an elevated position. Both involve the use of an eggbeater kick to generate upward forces.

The statement that can be derived on the basis of previously given data is that the quality of eggbeatar kick, also representing a base for a good result at the test of maximal dynamometric force, is a precondition for the raising and stabilisation of a body core from which a man initiate movements that are necessary to be performed by a torso and arms in order to perform a technically quality shoot with a big velocity. Therefore, it should be noted that for elite water polo players a throwing velocity primarily depends on the level of their maximal force.

Specific test for the estimation of a maximal dynamometric force (DYN) accomplished a statistically significant correlation with a body height, arm span, body mass and BMI. This means that water polo players with higher values of these morphological attributes obtained higher level of a maximal force. This is one additional very interesting data. Although the throwing velocity did not accomplish a statistically significant correlation with any morphological attribute, in this way we can indirectly conclude that a higher throwing velocity was accomplished by elite water polo players who, first of all, hada bigger body mass and higher body heights. After that, it can be said that the findings from this study directly coincide with the statement by Alcaraz et al. (2012) who concluded that exist a strong and significant correlation between conditioning and performance factors with anthropometrical parameters in elite water polo players, accordingly, with statement by Alcaraz et al. (2011), who argue that a physical (strength, power, throwing velocity) and anthropometrical factors are important for determining the outcomes in water polo.

\section{CONCLUSION}

Water polo is a physically and mentally very demanding sport discipline. One number of the factors that are very important for its quality changed along with its development. This is a strong reason because of which the researches of water polo game should be permanently carried out on all areas on which water polo depends. This research ascertained that a swimming speed of water polo players do not depend on anthropometric and specific motor qualities, but primarily on the technical skills. Also, a throwing velocity of elite water polo players depends directly only on a maximal strength, while it through a maximal strength indirectly accomplishes a correlation with a body mass and body height. This research shown that a higher level of a maximal dynamometric force is produced by elite water polo players with bigger body mass, body height, BMI and arm span. It also say that the water polo players with bigger body 
dimensions are stronger than water polo players with smaller values of these indicators.

In summary, it may be noted that the mutual correlation of anthropometric parameters and specific motor indicator plays a very important role in the quality of elite water polo game. However, within various water polo schools, the relation among morphologic and physiologic parameters is different and is inclined to constant changes. There is no unique and ideal morphologic-motor profile of elite water polo player. These profiles can resemble mutually, but they always have their specificities that are very important. Future studies should analyze those specificities.

\section{REFERENCES}

Alcaraz, P. E., Abraldes, J. A., Ferragut, C., Rodríguez, N., Argudo F. M., \& Vila, H. (2011). Throwing velocities, anthropometric characteristics, and efficacy indices of women's European water polo subchampions. Journal of Strength and Conditioning Research, 25(11), 30513058. doi: 10.1519/JSC.0b013e318212e20f

Alcaraz, P. E., Abraldes, J. A., Ferragut, C., Vila, H., Rodríguez, N., \& Argudo F. M. (2012).

Relationship Between Characteristics of Water Polo Players and Efficacy Indices. Journal of Strength and Conditioning Research, 26(7), 18521857. doi: 10.1519/JSC.0b013e318237ea4f

Anderson, M., Hopkins, W., Roberts, A., \& Pyne, D. (2008). Ability of test measures to predict competitive performance in elite swimmers. Journal of Sports Science, 26(2), 123-130. doi: 10.1080/02640410701348669

Barry, B., \& Maria, I. V. (2010). Leg length, body proportion, and health: A review with a note on beauty. International Journal of Environmental Research and Public Health, 7(3), 1047-1075. doi: 10.3390/ijerph7031047

Bloomfield, J., Blanksby, B. A., Ackland, T. R., \& Allison, G. T. (1990). The influence of strength training on overhead throwing velocity of elite water polo players. Australian Journal of Sience and Medicine in Sport, 22(3), 63-67.

Cazorla, G., \& Montpetit, R. R. (1988). Metabolic and Cardiac Responses of Swimmers, Modern Pentathletes, and Water Polo Players During Freestyle Swimming to a Maximum. In B. Ungerechts, and K. Wilke Reischle (Eds.), Swimming Science $V$. International Series on Sport Sciences (pp. 251-257). Champaign, IL: Human Kinetics.

Dopsaj, M., Matković, I., \& Zdravković, I. (2000). The relationship between $50 \mathrm{~m}$-freestyle results and characteristics of tethered forces in male sprint swimmers: a new approach to tethered swimming test. Facta Universitatis, 1(7), 15-22.

Ferragut, C., Abraldes, J. A., Vila, H., Rodríguez, N., Argudo F. M., \& Fernandes, R. J. (2011a).

Anthropometry and throwing velocity in elite water polo by specific playing position. Journal of Human Kinetics, 27(1), 31-44.

Ferragut, C., Vila, H., Abraldes, J. A., Argudo F. M., Rodríguez, N., \& Alcaraz, P. E. (2011b).

Relationship among maximal grip, throwing velocity and anthropometric parameters in elite water polo players. The Journal of Sports Medicine and Physical Fitness, 51(1), 26-32.

Fernandez, J. R., \& Vilas-Boas J. P. (2012). Time to exhaustion at the $\mathrm{VO}_{2}$ max velocity in swimming: A review. Journal of Human Kinetics, 32, 121-134.

Goon, D. T., Toriola A. L., Musa, D. I. \& Akusu, S. (2011). The relationship between arm span measurement and stature in Nigerian adults. Kinesiology, 43(1), 38-43.

Homma, M. (2000). Load above the water surface during the movements in synchronized swimming. Bulletin of sports methodology, 16, 1322.

Idrizović, K., Milošević, D., \& Pavlović, R. (2013). Physiological diferencess between top elite and elite waterpolo players. Sport Science, 6(2), 59-65.

Idrizović, K., Uljević, O., Ban, Đ., Spasić, M. \& Rausavljević, N. (2013). Sport-specific and anthropometric factors of quality in junior male water polo players. Collegium Antropologicum, 37(4), 1261-1266.

Joris H. J. J., Muijen Van, E., Ingen Schernau Van, G. J., \& Kemper, H. C. G. (1985). Force, velocity and energy flow during the overarm throw in female handball players. J. Biom, 18, 409-414. doi: 10.1016/0021-9290(85)90275-1

Knechtle, B., Baumann, B., Knechtle, P., \& Rosemann, T. (2011). What influences race performance in male open-water ultraendurance swimmers: Anthropometry or training? Human Movement, 11(1), 5-10.

Kondrič, M., Uljević, O., Gabrilo, G., Kontić, D., \& Sekulić, D. (2012). General anthropometric and specific physical fitness profile of high-level junior water polo players. Journal of Human Kinetics, 32, 157-165. doi: 10.2478/v10078-0120032-6

Lozovina, V., \& Pavičić, L. (2005). Anthropometric changes in elite male water polo players: Survey in 1980 and 1995. Croatian Medical Journal, 45, 202-205.

Lozovina, M., Durović, N., \& Katić, R. (2009). Position specific morphological characteristics of elite water polo players. Collegium Antropologicum, 33(3), 781-789. 
Lozovina, M., Lozovina, V., \& Pavičić, L. (2012). Morphological changes in elite male water polo players: Survey in 1980 and 2008. Acta Kinesiologica, 6(2), 85-90.

Lupo, C., Tessitore, A., Minganti, C., \& Capranica, L. (2010). Notational analysis of elite and subelite water polo matches. Journal of Strength and Conditioning Research, 24(1), 223-229. doi: 10.1519/JSC.0b013e3181c27d36

Marfell-Jones, M., Olds, T., Stew, A., \& Carter, L. (2006). International standards for anthropometric assessment. Potchefstroom, South Africa: The International Society for the Advancement of Kinanthropometry (ISAK).

Meckel, Y., Bishop, D., Rabinovich, M., Kaufman, L., Nemet, D., \& Eliakim A. (2013). Repeated Sprint Ability in Elite Water Polo Players and Swimmers and its Relationship to Aerobic and Anaerobic Performance. Journal of Sports Science and Medicine, 12(4),738-743.

Melchiorri, G, Castagna, C, Sorge R, \& Bonifazi, M. (2010). Game activity and blood lactate in men's elite water-polo players. Journal of Strength and Conditioning Research, 24(10), 2647-2651. doi: 10.1519/JSC.0b013e3181e3486b

Milanović, D., \& Vuleta, D. (2013). Association between morphological dimensions of water polo players and play performance indicators. Sport Mont, 11(37, 38, 39), 447-453.

Reeves, S. L., Varakamin, C., \& Henry, C. J. (1996). The relationship between arm-span measurements and height with special reference to gender and ethnicity. European Journal of Clinical Nutrition, 50(6), 398-400.

Sanders, R. H. (1998). Lifting performance in aquatic sports. In H. J. Riehle and M. M. Vieten (Eds), Proceedings book of XVI International Symposium on Biomechanics in Sports (pp. 25-39). Germany: University of Konstanz.

Sanders, R. H. (1999). Analysis of the eggbeater kick used to maintain height in water polo. Journal of Applied Biomechanics, 15, 284-291.

Siders, W. A., Lukaski, H. C., \& Bolonchuk, W. W. (1993). Relationships among swimming performance, body composition and somatotype in competitive collegiate swimmers. Journal of Sports Medicine and Physical Fitness, 33(2), 166-171.

Smith, H. K. (1998). Applied physiology of water polo. Sports Medicine, 26(5), 317-334. doi: 10.2165/00007256-199826050-00003

Snyder, P. (2008). Water polo for Players \& Techers of Aquatics. Los Angeles, CA: Los Angeles Olympic Foundation.

Steele, M. F., \& Chenier, T. C. (1990). Arm-span, height and age in black and white women. Annals of Human Biology, 17(6), 533-541. doi: 10.1080/03014469000001312

Goon, D. T., Toriola, A. L., Musa, D. I., \& Akusu, S. (2011). The relationship between arm span measurement and stature in Nigerian adults. Kinesiology, 43(1), 38-43.

Tsekouras, Y. E., Kavouras, S. A., Campagna, A., Kotsis, Y. P., Syntosi, S. S., Papazoglou, K., \& Sidossis, L. S. (2005). The anthropometrical and physiological characteristics of elite water polo players. European Journal of Applied Physiology, 95(1), 35-41. doi: 10.1007/s00421-005-1388-2

Van der Wende, K. (2005). The effects of game-specific task constraints on the outcome of the water polo shot. Auckland, New Zealand: Auckland University of Technology.

Vila, H., Ferragut, C., Argudo, F. M., Abraldes, J. A., Rodrígues, M., \& Alacid, F. (2009). Relationship between anthropometric parameters and throwing velocity in water polo players. Journal of Human Sport and Exercise, 4(1), 57-68. doi: 10.4100/jhse.2009.41.07

Zampagni, M. L., Casino, D., Benelli, P., Visani, A., Marcacci, M., \& De Vito, G. (2008).

Anthropometric and strength variables to predict freestyle performance times in elite master swimmers. Journal of Strength Conditioning Research, 22(4), 1298-1307. doi: 10.1519/ JSC.0b013e31816a597b

World Medical Association Declaration of Helsinki. (2103). Ethical principles for medical research involving buman subjects. Retrieved from http://jama. jamanetwork.com/ on 10/22/2013.
Received: March 23, 2014

Revision received: Jun 19, 2014

Accepted: Jun 19, 2014
Correspondence to:

Kemal Idrizović, PhD

Faculty for sport and physical education Džordža Vašingtona 6/176, 81000 Podgorica Montenegro

Phone: + 38267541617 E-mail: kemo@t-com.me 